\section{AN UNUSUAL CASE OF HEART-BLOCK}

\author{
BY
}

T. WARWICK PRESTON, M.D., M.R.C.P.

ASSISTANT PHYSICIAN, CROYDON GENERAL HOSPITAL ; CONSULTING PHYSICIAN, COUNTY BOROUGH OF CROYDON

The following case appears to present certain features sufficiently unusual to justify publication.

\section{Case Report}

The patient, an apparently healthy young woman of 31 , suddenly came over giddy at about 9 p.m. on October 23rd, 1933 ; she flushed, felt sick, and then fell on the floor unconscious. She shortly recovered, but between 9 and 11 p.m. she had three similar faints. Dr. McGuire of Croydon was called, and found her apex beating at 28 a minute; he

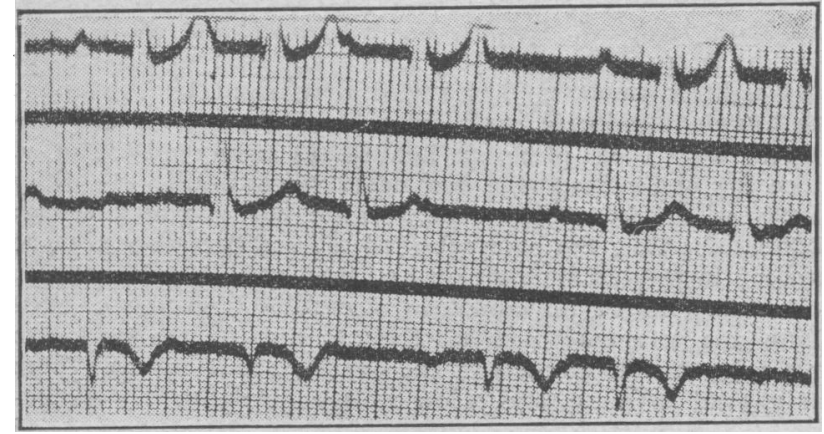

FIG. 1.

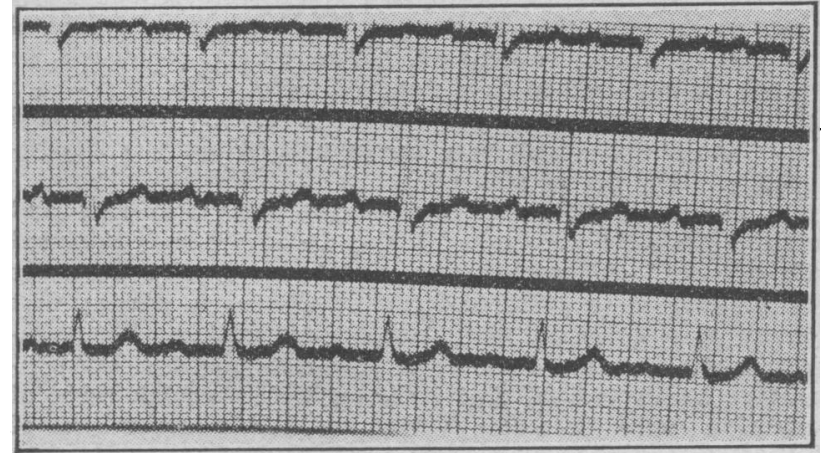

FIG. 2.

diagnosed complete heart-block, with Stokes-Adams syndrome. (I am indebted to Dr. McGuire for the particulars of onset.) The next day she was admitted to Croydon General Hospital, and was seen by me in the evening. Since 11 p.m. the previous day she had had no further attacks of faintness, and said that she now felt perfectly well. Her apex beat was regular at a rate of 30 a minute. Blood pressure, $120 / 78 \mathrm{~mm}$. Hg. She was afebrile. The urine contained a very faint haze of albumin: otherwise physical examination was negative. Unfortunately it was not possible to take a graphic record that evening, but there appeared to be no doubt that the case was one of complete heart-block.

On the morning of October 26th the cardiac condition showed a marked change. The apex beat was now considerably faster (56), but irregularly irregular. An electrocardiogram (Fig. 1) demonstrated auriculo-ventricular asynchronism, with an irregular action of the ventricle. On October 28th the heart, to physical examination, seemed normal. The apex rate was 60 and regular. The electrocardiogram was now ent:rely different from that taken two days previously. The picture will be seen now to be that of a sinus bradycardia, but it will be noted that there is marked prolongation of the P-R interval to 0.28 second (Fig. 2). A third tracing, taken on November 4th, was very similar to the previous one, but the P-R interval was now only 0.22 second (Fig. 3). A fnurth tracing, taken on November 11 th, revealed a normal rhythm, with the P-R interval 0.12 second. Further tracings, on December 9th, 1933, and on June 2nd, 1934, showed the same (Fig. 4).

The patient was kept in bed for three weeks; no drugs of any kind were administered. She was then allowed to get up gradually, and after a week was discharged from hospital. Since that time she has been back at her work as a clerk, and has had no symptoms of any kind.

During her stay in hospital she was afebrile throughout, and never displayed any signs or symptoms suggestive of rheumatic infection. The Wassermann reaction was negative. Apart from the faint haze of albumin at the first examination the urine was normal.

\section{Comment}

It is to be regretted that no electrocardiographic examination was made until three days after the onset of symptoms, but there can be little doubt that this was

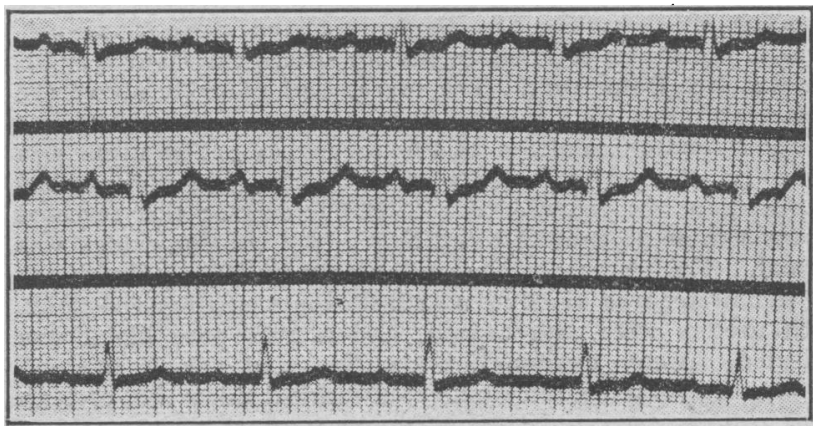

FIG. 3.

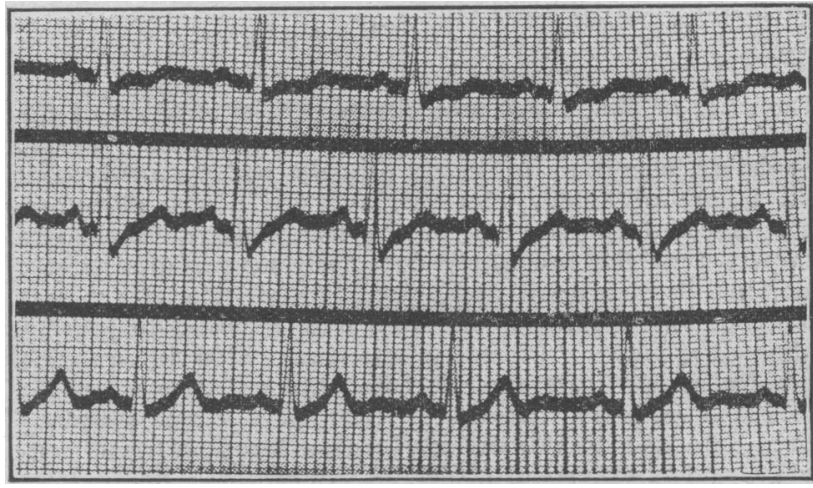

FIG. 4.

a case of complete heart-block. The gradual recovery to the normal rhythm is seen in the subsequent electrocardiograms, and it is probable that the heart has recovered without any kind of impairment.

Transitory attacks of partial heart-block are not uncommon. Complete heart-block is nearly always associated with severe and permanent damage to the bundle. Moreover, so far as I have been able to ascertain from the literature, transitory heart-block has usually occurred in the course of a definite febrile illness-usually rheumatic. In this instance investigation failed to reveal any cause for the condition.

Dr. William Langran of Axminster was presented, on April 2nd, with a gold watch, a cheque, and an album containing 1,358 names of subscribers, on the occasion of his retirement after forty-nine years' practice in the district. $\mathrm{He}$ had been medical officer of health for the Axminster rural and urban district councils, and surgeon to the cottage hospital. Replying after the presentation, Dr. Langran commented on the growth of Axminster since 1886, when it had poor housing, no public hall, and no cottage hospital, parish or urban councils, district nurses, health visitors, or sanitary inspector. 